\title{
Mobilização de competências nas atividades profissionais dos egressos de um programa de formação e aperfeiçoamento*
}

\author{
Carla Patrícia Bahry** \\ Suzana da Rosa Tolfo***
}

S UMÁRIO: 1. Introdução; 2. A abordagem das competências; 3. Programas de treinamento e desenvolvimento: caracterização e avaliação; 4. Método; 5. Descrição da organização estudada e de seu Programa de Formação e Aperfeiçoamento em Nível Superior; 6. Resultados; 7. Conclusões.

SUMMARY: 1. Introduction; 2. The competency approach; 3 . Training and development programs: characterization and assessment; 4. Method; 5. Description of the organization under study and of its Higher Education Program; 6. Results; 7. Conclusions.

PALAVRAS-CHAVE: gestão de pessoas; mobilização de competências; formação e aperfeiçoamento profissional.

KEY WORDS: people management; competency mobilization; professional training and development.

Este artigo revela como os egressos do Programa de Formação e Aperfeiçoamento em Nível Superior do Banco do Brasil, mestres ou doutores, percebem a mobilização, nos cargos em que estão alocados, das competências desenvolvi-

\footnotetext{
* Artigo recebido em out. 2005 e aceito em ago. 2006.

** Mestre em administração de empresas pela UFSC; analista da Universidade Corporativa Banco do Brasil. Endereço: SMDB, conj. 12B, lote 3, casa C — Lago Sul - CEP 71680-122, Brasília, DF, Brasil. E-mail: carlabahry@yahoo.com.br.

$\because * *$ Mestre em administração de empresas pela UFSC; doutora em administração de empresas pela UFRGS; professora dos programas de Pós-Graduação em Psicologia e em Administração da UFSC; coordenadora do Curso de Graduação em Psicologia da mesma universidade. Endereço: Departamento de Psicologia - CFH — UFSC — Campus Universitário Trindade, CEP 88040-970, Florianópolis, SC, Brasil. E-mail: srtolfo@yahoo.com.br.
} 
das nos programas de pós-graduação onde obtiveram a titulação. A pesquisa, descritiva, utilizou uma abordagem metodológica qualitativa e quantitativa. A coleta de dados foi feita por meio de pesquisa documental e de questionário. A população foi composta pelos funcionários que participaram do programa e já haviam retornado ao trabalho. O estudo demonstrou que os egressos desenvolveram diversos conhecimentos, habilidades e atitudes. De forma geral, eles têm conseguido mobilizar as competências desenvolvidas, embora essa mobilização pudesse ocorrer com maior intensidade. As conclusões mostram que os resultados do programa são positivos, mas poderiam ser melhores, e que fatores relacionados ao tipo de atividade exercida, à relação dessas atividades com a formação do egresso e ao suporte organizacional influenciam a intensidade de mobilização.

\section{Mobilizing competencies in the professional activities of the participants of a training and development program}

This article shows how the participants of the Banco do Brasil Higher Education Program who obtained a master's or a doctor's degree perceive the use, in their specific posts, of the competencies acquired during their graduate courses. The research, which is descriptive, adopted both a qualitative and quantitative methodological approach. The data was obtained from documents and questionnaires. The sample was formed by bank employees who took part in the program and who had already returned to work. The study indicates that the employees developed a new knowledge, as well as different skills and attitudes. In general terms, they have been able to mobilize the acquired competencies, but not to their full extent. The conclusions of this study indicate that the program has positive results, but could be improved, and that factors associated with the job activities, the relationship between them and the participants' training, as well as organizational support, influence the level of the mobilization.

\section{Introdução}

A nova dinâmica mundial, caracterizada pela globalização de mercados e por rápidas mudanças, apresenta desafios constantes para as organizações contemporâneas, que querem obter vantagem competitiva. Essas transformações têm feito com que a gestão das empresas, especialmente a gestão das pessoas que nelas trabalham, sofra mudanças com vistas a adequar-se às exigências do mercado. A partir da década de 1990, observa-se um alinhamento das políticas de gestão de recursos humanos às estratégias empresariais, por meio da incorporação do conceito de competência ao gerenciamento de pessoas (Fleury e Fleury, 2000). Dessa forma, ao determinar a sua estratégia competi- 
tiva, as empresas definem suas competências organizacionais essenciais, ou seja, suas core competences, e também as competências humanas necessárias para o seu respectivo negócio.

As competências essenciais, segundo Prahalad e Hamel (2000), representam os principais recursos da empresa e contribuem de maneira significativa para a percepção dos clientes em relação aos benefícios do produto final. As competências humanas, por sua vez, referem-se "(...) à combinação de conhecimentos, habilidades e atitudes (CHAs) que um indivíduo mobiliza para alcançar um determinado propósito no trabalho" (Abbad e Borges-Andrade, 2004:241).

A adoção da lógica da competência na gestão de pessoas pressupõe a preconização do desenvolvimento, da mobilização e da valorização das competências dos indivíduos. Nesse sentido, as organizações passam a atuar de maneira ativa no desenvolvimento de competências humanas, por meio de investimentos em programas de formação e aperfeiçoamento. Com eles, procuram proporcionar experiências que desenvolvam, fortaleçam e consolidem as competências dos indivíduos.

Muitas organizações têm se destacado pelos crescentes investimentos no desenvolvimento das competências de seus funcionários. Exemplo disso pode ser constatado nas organizações bancárias que, diante de um contexto altamente dinâmico e competitivo, precisam, além da utilização de novas tecnologias, de profissionais que possuam e desenvolvam continuamente as competências necessárias para atender as novas demandas organizacionais e as expectativas dos clientes. Iniciativas como a do Banco do Brasil, que criou, em 1997, o Programa de Formação e Aperfeiçoamento em Nível Superior, demonstram essa nova postura.

Segundo Ruas (1999), entretanto, grande parte dos saberes desenvolvidos nos programas de formação e aperfeiçoamento ficam circunscritos às suas vivências específicas. Muito pouco desses saberes é incorporado às atividades profissionais dos funcionários egressos, implicando baixo retorno em relação aos investimentos da organização e dos treinandos. Isso aumenta a preocupação, por parte das organizações, com a alocação dos funcionários egressos desses programas, em funções mais complexas, para que possam trazer vantagem competitiva por meio da mobilização das competências desenvolvidas. Dessa forma, este artigo identifica a percepção dos funcionários egressos do Programa de Formação e Aperfeiçoamento em Nível Superior do Banco do Brasil, titulados mestres ou doutores, sobre a mobilização, nos cargos em que estão alocados, das competências desenvolvidas nos programas de pós-graduação onde obtiveram a titulação. 
Para caracterizar o estudo, apresentam-se, a seguir, uma revisão da literatura sobre a abordagem das competências e sobre os programas de treinamento e desenvolvimento, o método utilizado e a caracterização do banco e de seu programa de formação e aperfeiçoamento. Ao final, são descritos resultados, discussões e conclusões.

\section{A abordagem das competências}

O conceito de competência encontra-se em construção (Le Boterf, 2003). Diversos autores vêm tratando da temática nos últimos anos, abordando-a por meio das mais variadas interpretações. Essas diversas abordagens dificultam uma uniformidade conceitual, mas permitem identificar uma unanimidade em relação ao fato de que a gestão por competências constitui um fator importante para a obtenção de vantagem competitiva no atual cenário em que as organizações estão inseridas. ${ }^{1}$ Em uma perspectiva genérica, a competência vem sendo entendida como a capacidade de a organização obter melhor desempenho do que seus concorrentes.

As competências podem ser classificadas como humanas (relacionadas ao indivíduo ou ao grupo de trabalho) e como organizacionais (relativas à organização em sua totalidade) (Brandão e Guimarães, 2001). O conceito de competência humana é articulado com base em três dimensões: conhecimentos, habilidades e atitudes (Durand, 1998; Gilbert, 1978; Ruas, 1999; Brandão e Bahry, 2005, entre outros).

Segundo Zarifian (2001), o conhecimento ou o "saber" é adquirido por meio da aprendizagem. É na absorção dos conhecimentos e na relação educativa que as competências normalmente são formadas e desenvolvidas. Para Le Boterf (2003), os conhecimentos podem ser desenvolvidos tanto na educação formal quanto na experiência profissional. A habilidade ou o "saber fazer" refere-se à capacidade de o indivíduo utilizar, nas situações de trabalho, os conhecimentos desenvolvidos. Nesse sentido, não são os diplomas ou os saberes que são julgados para o reconhecimento profissional do indivíduo, mas sua capacidade de manifestar competências e produzir efeitos importantes no trabalho (Zarifian, 2001). A atitude, por sua vez, pressupõe a predisposição da pessoa para atuar (se comportar) de determinada maneira diante de um objeto (Mar-

\footnotetext{
${ }^{1}$ Neste artigo não se pretende discutir as diversas correntes e abordagens conceituais do tema. Serão apresentados, apenas, os conceitos que foram mais relevantes para o desenvolvimento da pesquisa. 
tin-Baró, 1983). É importante ressaltar que a atitude e o comportamento, embora estejam relacionados, são conceitos distintos. A atitude é uma predisposição a reagir a um estímulo e é um determinante importante do comportamento do indivíduo, influenciando-o a agir de determinada maneira. No entanto, o fato de a atitude apresentar uma intenção de comportamento por parte do indivíduo não significa, necessariamente, que essa intenção será consumada. A consumação depende das circunstâncias e é por meio da ação que o comportamento é concretizado (Bowditch e Buono, 1992).

A expressão da competência ocorre quando o indivíduo “(...) gera um resultado no trabalho, decorrente da aplicação conjunta de conhecimentos, habilidades e atitudes - os três recursos ou dimensões da competência" (Carbone et al., 2005:44). Para Ruas (2005) a efetividade e a legitimação de uma competência ocorre por meio de ações em situações reais de trabalho, nas quais a articulação das suas principais dimensões (conhecimentos, habilidades e atitudes) ocorre.

Com a adoção da gestão por competências a organização procura orientar seus esforços no sentido de planejar, captar, desenvolver e avaliar as competências humanas e organizacionais necessárias para a consecução dos seus objetivos (Carbone et al., 2005). Sob essa perspectiva, tem-se evidenciado, principalmente, a criação de um clima favorável para promover o desenvolvimento das competências dos funcionários. Esse desenvolvimento, que ocorre por processos de aprendizagem, permite que os indivíduos possam assumir atribuições e responsabilidades mais complexas (Dutra, 2001). Para isso, as organizações buscam criar mecanismos para ampliar a capacidade e a velocidade da aprendizagem. Tais mecanismos envolvem a adoção de modelos, o desenvolvimento de sistemas educacionais, além de investimentos em outras alternativas, como os programas de treinamento e desenvolvimento, que têm uma função importante para a formação de competências, o que será abordado a seguir.

\section{Programas de treinamento e desenvolvimento: caracterização e avaliação}

As ações voltadas à aprendizagem podem ser consideradas atividades inerentes à gestão por competências. Os processos de aprendizagem formal nas organizações são fundamentais para o desenvolvimento de competências e estão associados às ações de treinamento e de desenvolvimento. Aprender implica mudar conhecimentos, habilidades e atitudes. A aprendizagem está, 
portanto, associada à noção de mudança e pode ser observada no trabalho por meio da comparação do desempenho do indivíduo antes e depois de um processo de aprendizagem. O desempenho resultante da aplicação de novas competências revela se o indivíduo aprendeu algo novo, pois mudou sua forma de atuar (Freitas e Brandão, 2005).

Nesse contexto, as ações de treinamento e de desenvolvimento ganharam importância fundamental, evoluindo de iniciativas esporádicas e isoladas para um processo contínuo e múltiplo. Elas referem-se, segundo Vargas (1996:127), à aquisição “(...) de conhecimentos capazes de provocar, a curto ou a longo prazo, uma mudança na maneira de ser e de pensar do indivíduo, por meio da internalização de novos conceitos, valores ou normas e da aprendizagem de novas habilidades". Borges-Andrade (2000) destaca que o processo de treinamento permite a aquisição de habilidades motoras ou intelectuais e informações, bem como o desenvolvimento de estratégias cognitivas e atitudes, que podem tornar o indivíduo mais competente para desempenhar vários papéis na organização. Para Abbad e Borges-Andrade (2004), o treinamento tem o objetivo de melhorar o desempenho do indivíduo em seu cargo. Já o desenvolvimento refere-se ao conjunto de experiências e oportunidades de aprendizagem que a organização oferece, para o crescimento pessoal do empregado, tornando-o capaz de aprender, sem focar um direcionamento específico. Borges-Andrade (2000) afirma ainda que algumas noções que pareciam mais restritas ao conceito de treinamento podem, no entanto, ser sorvidas pelo conceito de desenvolvimento, que é posto em prática, na atualidade, como estratégia da organização num contexto de competição acirrada por trabalho e emprego.

A avaliação dos processos de treinamento e desenvolvimento é considerada ferramenta estratégica para as organizações. Avaliar as ações de treinamento e desenvolvimento significa garantir que o esforço despendido, tanto em matéria de tempo quanto de energia e dinheiro, está gerando o retorno esperado pela organização. Esse retorno não é apenas financeiro, mas também pode se dar por meio de maior profissionalismo dos funcionários, pelo revigoramento da motivação e pela melhora nos processos de comunicação, entre outros. Para que as ações de treinamento e de desenvolvimento sejam consideradas investimentos, devem promover melhorias na organização, mediante a elevação do profissionalismo e do crescimento pessoal dos indivíduos. O processo de avaliação evidencia possíveis distanciamentos entre os objetivos fixados e os resultados obtidos, e permite empreender eventuais ações corretivas necessárias (Feuillette, 1991). 


\section{Método}

Esta pesquisa caracteriza-se como o estudo de um fenômeno, por meio de um caso, visto que foi empreendida em uma única organização, o Banco do Brasil, e investigou um fenômeno em sua realidade (Yin, 1984). É classificada fundamentalmente como descritiva, pois descreve as situações e os eventos observados (Roesch, 1999). Para seu desenvolvimento, foi adotada uma abordagem metodológica de natureza qualitativa, a fim de verificar as percepções dos sujeitos para interpretar os fenômenos comportamentais que ocorriam na organização. Foi utilizada, de modo combinado, uma abordagem quantitativa, por meio do uso de medidas de níveis nominal e ordinal para mensuração de alguns dados (Borges-Andrade e Zanelli, 2004).

A população que fez parte do universo da pesquisa foi composta pelos funcionários que participaram do Programa de Formação e Aperfeiçoamento em Nível Superior (beneficiados com bolsas para cursos de pós-graduação stricto sensu), criado em 1997, e já haviam retornado ao trabalho no banco no período em que se iniciou a coleta de dados.

A coleta de dados foi feita por meio de pesquisa em documentos da organização e de um questionário, composto de questões abertas e fechadas. Antes da aplicação do questionário foi realizado um teste para verificar se o enunciado, a escala e os itens do instrumento eram inteligíveis aos respondentes (validação semântica) (Pasquali, 1997).

Quanto ao modo de aplicação, o questionário foi enviado, inicialmente, pelo malote interno do Banco do Brasil acompanhado de uma carta de apresentação. Posteriormente, os questionários foram reenviados por e-mail. A coleta dos dados, com o questionário, ocorreu de 6 de setembro de 2004 a 23 de novembro de 2004. Foram remetidos 44 questionários, tendo retornado $32(72,73 \%)$.

Os dados obtidos nas respostas às questões fechadas do questionário receberam tratamento estatístico - estatística descritiva, por meio do Excel. Os dados obtidos nas respostas às questões abertas do questionário passaram por análise de conteúdo (Richardson et al., 1985). Também foi feita análise dos documentos da organização, o que possibilitou o levantamento de aspectos relevantes à investigação.

\section{Descrição da organização estudada e de seu Programa de Formação e Aperfeiçoamento em Nível Superior}

O Banco do Brasil foi fundado em 1808 e iniciou suas atividades em dezembro de 1809 (Peláez e Suzigan, 1981). Trata-se de uma organização financei- 
ra de economia mista, que tem como missão "Ser a solução em serviços e intermediação financeira, atender as expectativas de clientes e acionistas, fortalecer o compromisso entre os funcionários e a empresa e contribuir para o desenvolvimento do país" (Banco do Brasil, 2004a:1).

Atualmente, o banco está presente em 2.884 municípios, com 13.220 pontos de atendimento, e seu quadro funcional é composto de 82.216 funcionários, confirmando sua posição de maior organização financeira da América Latina (Banco do Brasil, 2004a, 2004c).

A educação empresarial representa uma das prioridades da organização. O Sistema de Educação Corporativa do Banco existe desde 1965. Em 11 de julho de 2002, foi criada a Universidade Corporativa Banco do Brasil. Atualmente, as ações de capacitação da Universidade Corporativa estão estruturadas em duas vertentes: Programas de Apoio e Estímulo à Educação Formal (Programa de Formação e Aperfeiçoamento em Nível Superior; e Programa de Aperfeiçoamento em Idiomas Estrangeiros); e Programas de Educação Empresarial (cursos; Ciclo de Palestras; BB MBA; Excelência Executiva; Novos Gestores; treinamento no exterior e outros eventos de atualização profissional) (Banco do Brasil, 2004b).

O Programa de Formação e Aperfeiçoamento em Nível Superior do Banco do Brasil foi criado em 1997. Com ele o banco fornece bolsas de estudo para cursos de graduação e pós-graduação lato e stricto sensu para os funcionários selecionados em processos seletivos internos. A concessão de bolsas de pós-graduação stricto sensu (mestrado e doutorado) objetiva desenvolver funcionários que possam prospectar e analisar as necessidades e tendências do mercado, contribuindo para que a organização obtenha resultados sustentáveis. O funcionário selecionado permanece afastado do trabalho no banco, exercendo a função de pesquisador e com a manutenção de sua remuneração integral, por um período que varia de acordo com o prazo mínimo fixado pela instituição de ensino para a conclusão de todas as etapas do treinamento. Depois de concluída e homologada a dissertação ou tese, o egresso pode fazer estágio probatório de 90 dias, a critério da diretoria ou unidade administrativa que patrocinou a bolsa do mestrado ou doutorado. Caso aprovado no estágio ou se este for dispensado, o funcionário é comissionado e começa a atuar na referida diretoria ou unidade. De 1997 a 2004, 97 funcionários foram beneficiados pelo programa com bolsas para pós-graduação stricto sensu (Banco do Brasil, 2004b).

A seguir, serão apresentados os principais resultados do estudo e, depois, as discussões e conclusões. 


\section{Resultados}

A caracterização dos sujeitos permitiu constatar que a maioria dos 32 respondentes é do sexo masculino (84,37\%), tem idade entre 31 e 40 anos (68,75\%), e tempo de trabalho no banco entre 16 e 25 anos (64,52\%). Quanto à formação dos respondentes, os cursos de graduação mais comuns foram o de economia $(24,25 \%)$ e o de administração de empresas $(21,21 \%)$. A maioria dos funcionários possui o título de mestre $(90,32 \%)$ e $93,74 \%$ das bolsas concedidas pelo programa foram para cursos de mestrado. Quanto à diretoria ou unidade administrativa de vinculação dos sujeitos durante a permanência no programa, observa-se maior concentração na DIR4 (18,74\%) e na DIR6 (15,62\%). Depois da conclusão do curso, $68,75 \%$ dos egressos permaneceram vinculados à diretoria ou unidade que patrocinou a sua bolsa para mestrado ou doutorado. A tabela 1, a seguir, apresenta os dados que caracterizam os sujeitos.

\begin{tabular}{|c|c|c|c|}
\hline \multicolumn{4}{|c|}{ Tabela 1} \\
\hline Variável & Descrição & $\begin{array}{c}\text { Freqüência } \\
\text { absoluta }\end{array}$ & $\begin{array}{l}\text { Freqüência } \\
\text { relativa (\%) }\end{array}$ \\
\hline \multirow[t]{2}{*}{ Sexo } & Masculino & 27 & 84,37 \\
\hline & Feminino & 5 & 15,63 \\
\hline \multirow[t]{2}{*}{ Idade } & 31 a 40 anos & 22 & 68,75 \\
\hline & 41 a 50 anos & 10 & 31,25 \\
\hline \multirow[t]{5}{*}{ Tempo de trabalho no banco } & 6 a 10 anos & 3 & 9,68 \\
\hline & 11 a 15 anos & 6 & 19,35 \\
\hline & 16 a 20 anos & 10 & 32,26 \\
\hline & 21 a 25 anos & 10 & 32,26 \\
\hline & 26 a 30 anos & 2 & 6,45 \\
\hline \multirow[t]{10}{*}{ Graduação } & Administração de empresas & 7 & 21,21 \\
\hline & Ciência da computação & 1 & 3,03 \\
\hline & Ciências contábeis & 3 & 9,09 \\
\hline & Comunicação & 2 & 6,06 \\
\hline & Direito & 1 & 3,03 \\
\hline & Economia & 8 & 24,25 \\
\hline & Engenharia & 4 & 12,12 \\
\hline & Estatística & 2 & 6,06 \\
\hline & Matemática & 2 & 6,06 \\
\hline & Outras & 3 & 9,09 \\
\hline
\end{tabular}




\begin{tabular}{|c|c|c|c|}
\hline Variável & Descrição & $\begin{array}{l}\text { Freqüência } \\
\text { absoluta }\end{array}$ & $\begin{array}{l}\text { Freqüência } \\
\text { relativa (\%) }\end{array}$ \\
\hline \multirow[t]{2}{*}{ Titulação atual } & Mestre & 28 & 90,32 \\
\hline & Doutor & 3 & 9,68 \\
\hline \multirow[t]{3}{*}{ Bolsa de estudos recebida do banco } & Mestrado & 30 & 93,74 \\
\hline & Doutorado & 1 & 3,13 \\
\hline & Ambos & 1 & 3,13 \\
\hline \multirow{15}{*}{$\begin{array}{l}\text { Diretoria ou unidade de } \\
\text { vinculação durante a } \\
\text { permanência no programa** }\end{array}$} & DIR1 & 1 & 3,13 \\
\hline & DIR2 & 1 & 3,13 \\
\hline & DIR3 & 1 & 3,13 \\
\hline & DIR4 & 6 & 18,74 \\
\hline & DIR5 & 1 & 3,13 \\
\hline & DIR6 & 5 & 15,62 \\
\hline & DIR7 & 2 & 6,25 \\
\hline & DIR8 & 3 & 9,37 \\
\hline & DIR9 & 2 & 6,25 \\
\hline & DIR10 & 1 & 3,13 \\
\hline & DIR11 & 1 & 3,13 \\
\hline & DIR12 & 2 & 6,25 \\
\hline & DIR13 & 4 & 12,48 \\
\hline & DIR14 & 1 & 3,13 \\
\hline & DIR15 & 1 & 3,13 \\
\hline \multirow{2}{*}{$\begin{array}{l}\text { Permanência na diretoria ou unidade } \\
\text { após o programa }\end{array}$} & Sim & 22 & 68,75 \\
\hline & Não & 10 & 31,25 \\
\hline
\end{tabular}

No que diz respeito aos conhecimentos desenvolvidos durante o programa, observou-se que a maioria dos egressos assinalou as opções: conhecer formas de realização de estudos teórico-empíricos para solucionar problemas e antecipar tendências (78,13\%); conhecer diferentes métodos estatísticos (75\%); e conhecer redes de informações para serem utilizadas como fontes de pesquisa (71,88\%). Esses conhecimentos são desenvolvidos, especialmente, em cursos de pós-graduação. Considerados saberes acadêmicos e adquiridos por meio da formação, ratificam o aprendizado dos sujeitos durante o programa. Ao descreverem outros conhecimentos que consideram ter desenvolvido, a maioria dos sujeitos (oito citações) apontou conhecimentos relacionados a técnicas e métodos de pesquisa, corroborando as informações anteriores. 
Ao serem questionados quanto à aplicação, nas atividades de trabalho, dos conhecimentos desenvolvidos durante o programa, pode-se constatar que a maioria dos egressos afirmou que aplica os conhecimentos em análises econômicas, financeiras e de crédito (oito citações), e em atividades de planejamento e na definição de estratégias da organização (sete citações).

Também foi possível verificar que alguns respondentes (sete citações) destacaram que: não aplicam, aplicam pouco, aplicam ocasionalmente, aplicam na medida do possível ou não conseguem identificar situações específicas de aplicabilidade dos conhecimentos desenvolvidos durante a permanência no programa, nas suas atividades de trabalho. Alguns sujeitos (duas citações) enfatizaram, também, que gostariam de estar aplicando melhor os conhecimentos desenvolvidos, mas que a organização não tem proporcionado plena oportunidade para que o façam. Outros respondentes (cinco citações), entretanto, afirmaram aplicar diariamente, nas suas atividades de trabalho, os conhecimentos desenvolvidos.

Ao fazer referência às habilidades desenvolvidas durante o programa, observou-se que a maioria dos egressos assinalou as opções: ser capaz de utilizar métodos estatísticos para geração e mensuração de resultados (68,75\%); ser capaz de identificar novas oportunidades de ação, por meio do acompanhamento das tendências e mudanças locais e globais (59,38\%); ser capaz de tratar as informações por meio do uso de novas tecnologias de gestão e informação (50\%); e ser capaz de identificar ameaças e oportunidades no mercado (50\%). Como se percebe, as habilidades parecem estar relacionadas com os conhecimentos apontados pelos sujeitos do estudo e referem-se à atividade de pesquisa e, também, ao ambiente de atuação dos funcionários. Quando foram questionados se haviam desenvolvido outras habilidades além das apresentadas, a maioria dos indivíduos (13 respondentes) não respondeu e seis pessoas afirmaram não ter desenvolvido outras habilidades. Cabe salientar, entretanto, que alguns sujeitos (cinco citações) mencionaram ter desenvolvido habilidades de pesquisa e relacionadas ao meio acadêmico. Outros respondentes (cinco citações) afirmaram ter desenvolvido habilidades de liderança e de relacionamento interpessoal.

Ao descrever a forma como aplicam as habilidades desenvolvidas no programa, um conjunto de respondentes (cinco citações) afirmou que essa aplicação ocorre com freqüência. Outros egressos destacaram que aplicam as habilidades desenvolvidas fazendo planejamento e definindo estratégias (quatro citações), fazendo análises (quatro citações) e em atividades de gestão e trabalho em equipe (quatro citações).

Constatou-se, também, que dois respondentes afirmaram não aplicar, em suas atividades de trabalho, as habilidades desenvolvidas. Outros quatro 
egressos não responderam à pergunta. Alguns sujeitos (cinco citações) afirmaram que aplicam as habilidades desenvolvidas, no entanto essa aplicação é pouco freqüente ou dá-se de forma restrita ou na medida do possível.

Em relação às atitudes desenvolvidas durante o programa e aos comportamentos ${ }^{2}$ observou-se que a maioria dos egressos assinalou as opções: buscar permanentemente o autodesenvolvimento (84,38\%); manter boas relações interpessoais $(71,88 \%)$; e ter disposição para ouvir e receber feedback $(71,88 \%)$. Ao serem questionados se haviam desenvolvido outras atitudes além das apresentadas, a maioria dos indivíduos (20 egressos) não respondeu e seis afirmaram não ter desenvolvido outras atitudes.

Também foi verificada a expressão das atitudes sob a forma de comportamentos manifestos na execução das atividades de trabalho. Os sujeitos afirmaram que essa expressão de atitudes dá-se: por meio do trabalho em equipe (quatro citações); na gestão de pessoas e liderança (duas citações); ouvindo as pessoas e emitindo opiniões (duas citações); na atuação com ética (duas citações); entre outras. Onze pessoas não responderam a essa questão, uma afirmou que concretiza pouco as atitudes desenvolvidas e outra declarou que as atitudes desenvolvidas não são concretizadas em comportamentos no trabalho.

Quanto à intensidade de mobilização, como pode ser observado na tabela 2 , constatou-se que quase metade dos respondentes $(43,75 \%)$ afirmou estar mobilizando com muita intensidade as competências desenvolvidas, enquanto outros afirmaram estar mobilizando totalmente $(15,62 \%)$. Alguns respondentes apontaram estar mobilizando com intensidade mediana (25\%) e os demais afirmaram estar mobilizando com pouca $(12,50 \%)$ ou nenhuma intensidade $(3,13 \%)$.

Do total de egressos que afirmaram mobilizar com muita $(43,75 \%)$ ou total $(15,62 \%)$ intensidade as competências desenvolvidas (19 respondentes), 68,42\% permaneceram vinculados, após egressar do programa, à diretoria ou unidade que patrocinou a bolsa de estudos. Esses dados podem ser indicativos de que essa permanência permite que os sujeitos apliquem de maneira mais efetiva, na organização, o que aprenderam, especialmente por terem desenvolvido suas pesquisas em áreas de interesse das patrocinadoras.

\footnotetext{
${ }^{2}$ Embora sejam distintos os conceitos de atitude e comportamento, a literatura especializada descreve que a atitude é um determinante importante do comportamento do indivíduo, influenciando-o a agir de determinada maneira (Bowditch e Buono, 1992). Dessa forma, neste artigo, as atitudes e os comportamentos dos respondentes serão analisados em conjunto.
} 


\begin{tabular}{|c|c|c|c|}
\hline \multicolumn{4}{|c|}{$\begin{array}{c}\text { Tabela } 2 \\
\text { Mobilização das competências desenvolvidas } \\
\text { durante o programa* }\end{array}$} \\
\hline Variável & Descrição & $\begin{array}{l}\text { Freqüência } \\
\text { absoluta }\end{array}$ & $\begin{array}{l}\text { Freqüência } \\
\text { relativa (\%) }\end{array}$ \\
\hline $\begin{array}{l}\text { Intensidade com que as competências são } \\
\text { mobilizadas }\end{array}$ & $\begin{array}{l}\text { Nenhuma } \\
\text { Pouca } \\
\text { Mediana } \\
\text { Muita } \\
\text { Total }\end{array}$ & $\begin{array}{r}1 \\
4 \\
8 \\
14 \\
5\end{array}$ & $\begin{array}{r}3,13 \\
12,50 \\
25,00 \\
43,75 \\
15,62\end{array}$ \\
\hline $\begin{array}{l}\text { Possibilidade de mobilizar as competências } \\
\text { de forma mais efetiva }\end{array}$ & $\begin{array}{l}\text { Sim } \\
\text { Não }\end{array}$ & $\begin{array}{r}23 \\
8\end{array}$ & $\begin{array}{l}74,20 \\
25,80\end{array}$ \\
\hline
\end{tabular}

Ao justificarem suas opções (muita e total intensidades - 59,37\%), alguns respondentes (quatro citações) mencionaram apenas os conhecimentos desenvolvidos, reforçando o caráter mais acadêmico dos cursos de mestrado ou doutorado, que parecem privilegiar o desenvolvimento da dimensão cognitiva. Outros egressos afirmaram mobilizar com muita intensidade as competências desenvolvidas, em virtude de realizarem um trabalho não-rotineiro (duas citações); de utilizarem técnicas específicas aprendidas durante o mestrado ou doutorado (duas citações); de desenvolver pesquisas (uma citação); e de utilizar o embasamento teórico (uma citação).

Entre os egressos que afirmaram mobilizar com intensidade mediana (25\%) as competências desenvolvidas durante o programa, 50\% (quatro respondentes) permaneceram vinculados à diretoria ou unidade que patrocinou a bolsa de mestrado ou doutorado e os outros 50\% (quatro respondentes) passaram a atuar em outras áreas do banco. A equivalência entre o número de egressos que permaneceram e o número dos que não permaneceram vinculados à patrocinadora, após o programa, pode ser um indicativo de que, nesses casos, a intensidade de mobilização não está diretamente relacionada com a permanência do funcionário na diretoria ou unidade que patrocinou o seu mestrado ou doutorado.

Procedeu-se, igualmente, a análise das justificativas dadas pelos egressos que manifestaram mobilizar medianamente $(25 \%)$ as competências desenvolvidas. Foi observado, nas justificativas, que a maioria dos egressos destacou 
apenas a mobilização dos conhecimentos desenvolvidos, o que não caracteriza, necessariamente, a ação competente, visto que esta decorre da aplicação conjunta de conhecimentos, habilidades e atitudes. Eles também demonstraram, por meio de suas respostas, que alguns fatores como: o trabalho que precisa ser executado diariamente e a demanda de apenas algumas competências desenvolvidas; o curto prazo para solução de demandas; a alocação em área pouco relacionada com a sua formação; a falta de sensibilidade dos gestores; e a exigência de conhecimentos mais normativos têm limitado a mobilização das competências desenvolvidas.

Todos os egressos que afirmaram estar mobilizando com pouca $(12,50 \%)$ ou nenhuma $(3,13 \%)$ intensidade, em seus cargos atuais, as competências desenvolvidas durante o programa continuaram vinculados às diretorias ou unidades que patrocinaram suas bolsas de estudos.

Um dos egressos justificou a pouca mobilização por estar alocado em uma área que não é condizente com a sua formação. Um outro, que também afirmou estar mobilizando pouco as competências desenvolvidas, destacou a "distância entre a pós-graduação stricto sensu e as questões do dia-a-dia". Essa "distância" também foi mencionada, de maneiras diferentes, por outros egressos. O funcionário egresso que afirmou mobilizar com nenhuma intensidade, em seu cargo atual, as competências desenvolvidas durante o programa, justificou sua opção afirmando que não há estímulo para ascensão na organização e que a estrutura é rígida e não permite a expansão.

Ao serem questionados se acreditavam que poderiam estar mobilizando de maneira mais efetiva as competências desenvolvidas, a maioria dos egressos (74,20\%) afirmou que sim, conforme pôde ser observado na tabela 2.

Entre os egressos que afirmaram mobilizar totalmente (cinco respondentes), em seus cargos, as competências desenvolvidas durante o programa, dois acreditam que poderiam estar mobilizando de maneira mais efetiva, dois acreditam que não e um não respondeu. Os egressos que acreditam que poderiam mobilizar mais efetivamente as competências desenvolvidas, descreveram questões relacionadas com o delineamento dos processos do banco e com a sua alocação. Esses dados podem indicar que eles reconhecem que, embora a mobilização seja total, sempre é possível melhorar. Dos dois egressos que afirmaram acreditar que não poderiam estar mobilizando mais efetivamente as competências desenvolvidas, apenas um justificou sua opção, afirmando estar utilizando plenamente as suas competências.

Entre os egressos que afirmaram mobilizar muito (14 respondentes), em seus cargos, as competências desenvolvidas durante o programa, 10 acreditam que poderiam estar mobilizando de maneira mais efetiva e quatro acreditam que não. Os egressos que afirmaram acreditar que poderiam mobilizar de ma- 
neira mais efetiva justificaram que isso seria possível por meio de: ampliação da atuação da organização na área de sua formação; alocação em área mais relacionada com a sua formação; maior preocupação da organização em aproveitar os conhecimentos adquiridos pelos funcionários; maior inovação por parte da organização; atuação como instrutor interno e multiplicador de conhecimentos; atuação em área que permita a tomada de decisões; busca pessoal por atualização; e compartilhamento de conhecimentos com outra pessoa. Já os funcionários egressos que afirmaram acreditar que não poderiam mobilizar de maneira mais efetiva, em seus cargos, as competências desenvolvidas, destacaram que: considera-se alocado de forma adequada; atua corriqueiramente em projetos especiais que requerem a mobilização das competências; a área de atuação permite o desenvolvimento de muitas competências ao mesmo tempo; e o mestrado abriu portas dentro e fora da organização.

Entre os funcionários egressos que afirmaram mobilizar medianamente (oito respondentes), em seus cargos, as competências desenvolvidas durante o programa, seis afirmaram que poderiam mobilizar de maneira mais efetiva e dois afirmaram que não. Ao afirmar que acreditam que poderiam mobilizar mais efetivamente as competências desenvolvidas, os egressos destacaram questões como: os saberes desenvolvidos no mestrado acadêmico não são muito aplicáveis na organização; a organização não está preparada para compartilhar assuntos com fundamentos acadêmicos e as exigências operacionais; a necessidade de alocação em áreas mais relacionadas com a sua formação; e a omissão do programa na recolocação dos funcionários egressos. Dos dois funcionários egressos que afirmaram acreditar que não poderiam mobilizar mais efetivamente, em seus cargos, as competências desenvolvidas, apenas um justificou sua resposta, afirmando que isso ocorre porque as competências que foram desenvolvidas são muito específicas.

Todos os funcionários egressos que afirmaram mobilizar pouco (quatro respondentes), em seus cargos, as competências desenvolvidas durante o programa, acreditam que poderiam mobilizá-las de maneira mais efetiva. Ao justificarem por que acreditavam que poderiam estar mobilizando-as mais efetivamente apontaram as mesmas dificuldades percebidas por outros sujeitos: o tipo de formação que a pós-graduação stricto sensu proporciona; a alocação em função que requer pouca mobilização das competências desenvolvidas; e o reaproveitamento dos egressos.

O funcionário egresso que afirmou mobilizar com nenhuma intensidade, em seu cargo, as competências desenvolvidas durante o programa também acredita que poderia mobilizá-las de maneira mais efetiva. Ressalta-se que não houve justificativa para sua opção. 


\section{Conclusões}

A temática da avaliação de ações formais voltadas para o desenvolvimento de competências e seu compartilhamento nas organizações é complexa e relevante de ser investigada. A verificação da mobilização, nas atividades profissionais dos treinandos, das competências desenvolvidas em programas de capacitação, torna-se primordial para o seu constante aperfeiçoamento.

Com base no estudo foi possível demonstrar que os principais conhecimentos desenvolvidos pelos funcionários egressos, durante a permanência no programa, foram relativos a saberes acadêmicos, bem como a técnicas e métodos de pesquisa e ensino. Esses conhecimentos demonstram congruência com o tipo de formação que o programa proporciona aos egressos. Tais conhecimentos parecem atender ao objetivo do programa, visto que, para prospectar e analisar as necessidades e tendências do mercado para geração de resultados sustentáveis, é importante que os sujeitos tenham conhecimento e experiência em pesquisa. Quanto à aplicação dos conhecimentos desenvolvidos, verificou-se que um número significativo de egressos afirmou que passou a atuar em atividades de análises econômicas, financeiras e de crédito e no planejamento e na definição de estratégias da organização. Isso pode ser justificável porque o banco concede bolsas para desenvolvimento de pesquisas em áreas de conhecimento nas quais possui interesse estratégico. Constatou-se, então, que a organização parece procurar estabelecer uma ligação entre suas estratégias e o desenvolvimento de seus funcionários, especialmente no que se refere aos conhecimentos desenvolvidos e à forma como esses são aplicados nas atividades de trabalho dos egressos.

A análise das principais habilidades desenvolvidas pelos funcionários egressos, durante a permanência no programa, demonstrou que elas parecem estar relacionadas aos principais conhecimentos e dizem respeito à atividade de pesquisa. Também estão relacionadas ao ambiente de atuação dos funcionários. Constatou-se, igualmente, que parece haver um alinhamento entre a aplicação dos conhecimentos e das habilidades desenvolvidas durante o programa, visto que alguns egressos afirmaram aplicar suas habilidades em atividades de planejamento e na definição de estratégias, em análises e em gestão, bem como no trabalho em equipe. Percebeu-se, entretanto, que nas questões vinculadas às habilidades, houve um número mais reduzido de respostas do que nas relacionadas aos conhecimentos. Isso poderia ser justificado pelo fato de que o desenvolvimento de habilidades está mais relacionado à prática profissional diária, ao passo que o desenvolvimento de conhecimentos está mais relacionado ao tipo de formação obtida por meio do programa. 
A análise das principais atitudes e comportamentos desenvolvidos pelos funcionários egressos, durante a permanência no programa, demonstrou que a busca permanente pelo autodesenvolvimento, a manutenção de boas relações interpessoais e a disposição para ouvir e receber feedback foram mais destacadas. Essas atitudes e comportamentos podem permitir que os funcionários melhorem suas atuações profissionais no atual cenário em que as organizações bancárias estão inseridas. Todas as atitudes que foram apontadas pelos funcionários egressos, se concretizadas em comportamentos, podem gerar resultados positivos no trabalho. Os comportamentos, que podem ser determinados, em certa medida, pelas atitudes dos indivíduos, também apontam para a mesma direção e caracterizam a ação competente.

Quanto à intensidade de mobilização, nos cargos atuais, das competências desenvolvidas pelos funcionários egressos, pôde-se perceber que mais da metade deles está mobilizando muito ou totalmente essas competências. Esses resultados podem indicar que o programa tem trazido resultados positivos para a organização, uma vez que a maioria dos funcionários egressos consegue efetivar e legitimar as competências desenvolvidas, por meio de ações em situações reais de trabalho. A análise dos dados demonstrou também que parte dos funcionários egressos (59\%) que permaneceram vinculados às diretorias ou unidades que os patrocinaram estão conseguindo mobilizar, nos seus cargos atuais, muito ou totalmente as competências desenvolvidas. Isso pode significar, então, que a permanência do funcionário na diretoria ou unidade patrocinadora da bolsa nem sempre representa garantia de alta mobilização das competências desenvolvidas.

De modo geral, constatou-se que há mobilização das competências desenvolvidas, mas, segundo a maioria dos egressos, ela poderia ocorrer com mais intensidade. Isso demonstra que, na percepção deles, as suas competências poderiam ser melhor aproveitadas pela organização. A análise dos dados demonstrou que questões relacionadas ao tipo de atividade exercida, à relação dessas atividades com a formação do egresso e ao suporte organizacional oferecido influenciam a intensidade de mobilização de competências. Dessa forma, percebeu-se que, por mais que os resultados obtidos pela organização sejam positivos, ainda podem ser melhorados, especialmente se ela investir mais no suporte aos funcionários egressos do programa.

Para que os resultados sejam melhorados, é importante que as diretorias ou unidades patrocinadoras das bolsas para mestrado ou doutorado estejam mais bem preparadas para receber os funcionários egressos, aprimorando o suporte organizacional à mobilização das competências desenvolvidas. Esse suporte envolveria orientação, incentivo à aplicação, informação direcional, ambiente favorável, entre outros aspectos. Os egressos poderiam, inclusive, ser alocados 
em cargos que demandassem atividades mais relacionadas com as competências desenvolvidas, gerando maior mobilização e retorno em relação aos investimentos da organização.

Outra questão levantada por alguns funcionários egressos refere-se ao fato de que a pós-graduação stricto sensu enfatiza a formação de pesquisadores. A maioria deles alegou que, após o retorno à organização, não realiza atividades especificamente voltadas à pesquisa, gerando questionamentos quanto à efetiva mobilização das competências desenvolvidas. Entretanto, de forma geral, pode-se inferir, com base nas respostas dos egressos, que as funções que eles desempenham pressupõem a identificação de fenômenos e problemas e de perguntas a serem respondidas por meio de procedimentos (método), além do conhecimento de situações, análises, diagnósticos e também inferências quanto às formas de atuação e aos possíveis resultados de cada ação. Dessa forma, embora realizem atividades relacionadas com processos de pesquisa, parece que esses sujeitos não visualizam essa relação. Além disso, o desenvolvimento de competências, por processos de aprendizagem, que ocorreu durante o programa, pode permitir que os funcionários egressos executem outras tarefas e assumam responsabilidades mais complexas, não precisando, necessariamente, atuar em atividades de pesquisa.

Finalmente, espera-se que este artigo tenha oferecido contribuições de ordem prática, não somente ao Banco do Brasil, mas também às demais organizações, para que elas avaliem suas práticas de gestão de pessoas, pela importância do desenvolvimento e da mobilização de competências, bem como da avaliação dos programas de formação e aperfeiçoamento, no sentido de verificar sua efetividade. Do ponto de vista acadêmico, espera-se ter contribuído para o debate teórico acerca de um conceito polêmico como o de competências, bem como para a formulação de novas hipóteses de estudo.

\section{Referências bibliográficas}

ABBAD, G. da S.; BORGES-ANDRADE, J. E. Aprendizagem humana em organizações de trabalho. In: ZANELLI, J. C.; BORGES-ANDRADE, J. E.; BASTOS, A. V. B. (Orgs.). Psicologia, organizações e trabalho no Brasil. Porto Alegre: Artmed, 2004.

BANCO DO BRASIL. Retrato da empresa. Disponível em: <www.bb.com.br>. Acesso em: 9 out. 2004a.

Educação corporativa. Universidade Corporativa Banco do Brasil. Disponível em: <www.bb.com.br>. Acesso em: 12 out. 2004b.

Diretoria gestão de pessoas: informações gerenciais. out. 2004c.

Rap Rio de Janeiro 41(1):125-44, Jan./Fev. 2007 
BORGES-ANDRADE, J. E. Desenvolvimento de medidas em avaliação de treinamento. In: ENCONTRO ANUAL DA ANPAD, 24., Florianópolis, 2000. Anais... Florianópolis: Anpad, 2000.

ZANELLI, J. C. Psicologia e produção de conhecimento em organizações e trabalho. In: ZANELLI, J. C.; BORGES-ANDRADE, J. E.; BASTOS, A. V. B. (Orgs.). Psicologia, organizações e trabalho no Brasil. Porto Alegre: Artmed, 2004.

BOWDITCH, J. L.; BUONO, A. F. Elementos de comportamento organizacional. São Paulo: Pioneira, 1992.

BRANDÃO, H. P.; BAHRY, C. P. Gestão por competências: métodos e técnicas para mapeamento de competências. Revista do Setor Público, v. 56, n. 2, abr./jun. 2005.

; GUIMARÃES, T. de A. Gestão de competências e gestão de desempenho: tecnologias distintas ou instrumentos de um mesmo construto? Revista de Administração de Empresas, São Paulo, v. 41, n. 1, p. 9-15, jan./mar. 2001.

CARBONE, P. P. et al. Gestão por competências e gestão do conhecimento. Rio de Janeiro: FGV, 2005.

DURAND, T. Forms of incompetence. In: INTERNATIONAL CONFERENCE ON COMPETENCE-BASED MANAGEMENT, 4. Proceedings... Oslo: Norwegian School of Management, 1998.

DUTRA, J. S. Gestão de pessoas com base em competências. In: (Org.). Gestão por competências. São Paulo: Gente, 2001.

FEUILLETTE, I. RH: o novo perfil do treinador. Como preparar, conduzir e avaliar um processo de treinamento. São Paulo: Nobel, 1991.

FLEURY, A.; FLEURY, M. T. L. Estratégias empresariais e formação de competências: um quebra-cabeça caleidoscópico da indústria brasileira. São Paulo: Atlas, 2000.

FREITAS, I. A.; BRANDÃO, H. P. Trilhas de aprendizagem como estratégia para desenvolvimento de competências. In: ENCONTRO ANUAL DA ANPAD, 29., Brasília, 2005. Anais... Brasília: Anpad, 2005.

GILBERT, T. F. Human competence: engineering worthy performance. New York: McGrawHill Book Company, 1978.

LE BOTERF, G. Desenvolvendo a competência dos profissionais. Porto Alegre: Artmed, 2003.

MARTIN-BARÓ, I. Acción e ideologia: psicologia social desde centroamérica. San Salvador: UCA, 1983.

PASQUALI, L. Psicometria: teoria e aplicações. Brasília: Universidade de Brasília, 1997. 
PELÁEZ, C. M.; SUZIGAN, W. História monetária do Brasil. Brasília: Universidade de Brasília, 1981.

PRAHALAD, C. K.; HAMEL, G. A competência essencial da corporação. In: ULRICH, D. (Org.). Recursos humanos estratégicos: novas perspectivas para os profissionais de RH. São Paulo: Futura, 2000.

RICHARDSON, R. J. et al. Pesquisa social: métodos e técnicas. São Paulo: Atlas, 1985.

ROESCH, S. M. A. Projetos de estágio e de pesquisa em administração. São Paulo: Atlas, 1999.

RUAS, R. A problemática do desenvolvimento de competências e a contribuição da aprendizagem organizacional. In: SEMINÁRIO INTERNACIONAL COMPETITIVIDADE BASEADA NO CONHECIMENTO. Anais... São Paulo, 1999.

. Gestão por competências: uma contribuição à estratégia das organizações. In: ANTONELLO, C. S.; BOFF, L. H. (Orgs.). Aprendizagem organizacional e competências. Porto Alegre: Bookman, 2005.

VARGAS, M. R. M. Treinamento e desenvolvimento: reflexões sobre seus métodos. Revista de Administração, São Paulo, v. 31, n. 2, p. 126-136. abr./jun. 1996.

YIN, R. K. Case study research: design and methods. California: Sage Publications, 1984.

ZARIFIAN, P. Objetivo competência: por uma nova lógica. São Paulo: Atlas, 2001. 